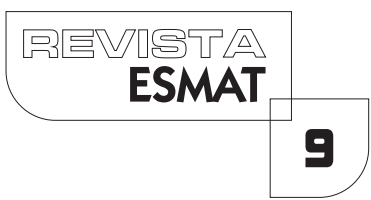

\title{
A CIDADE DE PALMAS: A SUSTENTABILIDADE EM QUESTÃO
}

Suyene Monteiro da Rocha

Mestre em Ciências do Ambiente pela Universidade Federal do Tocantins e doutoranda em Biodiversidade e Biotecnologia pela Rede Bionorte. Docente da Universidade Federal do Tocantins - UFT. Editora Executiva da Revista Vertentes do Direito - UFT.

\section{Gustavo Paschoal Teixeira de Castro Oliveira}

Doutorando em Direito das Relações Internacionais pelo Centro Universitário de Brasília. Mestre em Direito, Constituição e Processo - pela Universidade de Ribeirão Preto. Advogado. Docente na Universidade Federal do Tocantins e Coordenador do Curso de Direito no Centro Universitário Luterano de Palmas - CEULP/ULBRA.

\section{RESUMO}

A maioria da população mundial vive em ambiente urbano, assim, o espaço citadino tem sido palco de convergências e divergências do viver em coletividade. $\bigcirc$ acesso à cidade tem evidenciado encalços e percalços àqueles que nela estão. Como forma de mitigar os impactos do quantitativo de indivíduos na urbe, políticas públicas têm surgido, com o fito de se organizar o que por vezes está desordenado, orientar o crescimento urbano, melhorar a qualidade de vida. Se a maioria das cidades é fruto de ocupação desordenada, no cerrado brasileiro a busca foi de outra perspectiva. Cidades foram planejadas: Goiânia-GO, Brasília-DF e Palmas-TO, cronologicamente, a partir de um anseio de ocupação do planalto brasileiro de forma que o espaço atendesse às necessidades de toda a coletividade, mobilidade, saúde, moradia, segurança, educação. Sob esse olhar da cidade como produto de equidade a todos que nela estão inseridos, e da proposta da "cidade sustentável", o trabalho faz uma análise das políticas públicas brasileiras de gestão da cidade, com foco na cidade de Palmas-TO. Para tal, traça-se sua criação, estruturação e estrutura atual, com consequente análise da sustentabilidade. Ao trazer à baila esses atributos, o artigo se propõe a uma visão crítico-reflexiva da gestão do ambiente urbano e sua organização, num contexto tecnicamente "controlado" pelo processo de ocupação ordenada a partir de um projeto. $\bigcirc$ objeto de estudo é a cidade 


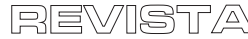

ESMAT

SUYENE MONTEIRO DA ROCHA / GUSTAVO PASCHOAL T. DE CASTRO OLIVEIRA

de Palmas-TO, tendo como luz a relação da construção à complexa e debatida cidade sustentável. A metodologia utilizada neste trabalho centra-se no estudo bibliográfico de caráter descritivo-analítico. A pesquisa focaliza-se num prisma qualitativo, e não probabilístico.

PALAVRAS-CHAVE: Ambiente urbano. Acesso à cidade. Políticas públicas. Cidade sustentável.

\section{RESUMEN}

La mayor parte de la población mundial vive en un entorno urbano, por lo que el espacio de la ciudad ha sido convergencias y divergencias etapa de la vida en comunidad. E acceso a la ciudad ha mostrado contratiempos a los que están en ella. Con el fin de mitigar los impactos de la cantidad de individuos en la metrópolis, han surgido las políticas públicas, con el objetivo de organizar lo que a veces desordenada, orientar el crecimiento urbano, mejorar la calidad de vida. Si la mayoría de las ciudades es el resultado de la ocupación desordenada en el cerrado brasileño la búsqueda fue desde otra perspectiva. Se planearon Ciudades: Goiânia GO, Brasilia-DF y Palmas- TO, cronológicamente, desde una ocupación anhelo de la meseta brasileña para que el espacio sería satisfacer las necesidades de toda la comunidad, la movilidad, la salud, la vivienda, la seguridad, la educación. Bajo este punto de vista de la ciudad como producto de renta variable de todo el mundo en que se inserta, y la propuesta de "ciudad sostenible", el trabajo analiza las políticas públicas brasileñas de gestión de la ciudad, centrándose en Palmas-TO. Por esta llamar su creación, estructura y estructura actual, con el consiguiente análisis de la sostenibilidad. Al traer a la palestra estos atributos, el artículo propone una visión crítica reflexiva de la gestión del medio ambiente urbano y de su organización, en un contexto técnicamente "controlada" por el proceso de ocupación ordenada de un proyecto. El objeto de estudio es la ciudad de Palmas/TO con la luz como la relación de la construcción del complejo y debatido ciudad sostenible. La metodología utilizada en este estudio se centra en el estudio bibliográfico de la descriptiva analítica. La investigación se centra en un prisma probabilístico cualitativa y no.

PALAVRAS CLAVE: Medio ambiente urbano. Acceso a la ciudad. Las políticas públicas. La ciudad sostenible. 


\section{CONSIDERAÇÕESINICIAIS}

Historicamente, o surgimento das primeiras cidades, mesmo no conceito objetivo de aglomeramentos populacionais, deu-se após a superação da fase nômade e a consolidação do sedentarismo oriundo da descoberta de novas tecnologias, preponderantemente da agricultura. Nessa linha de pensamento, segundo Carlos (1999, p. 58), no momento em que o homem deixa de ser nômade, fixando-se no solo como agricultor, é dado o primeiro passo para a formação das cidades.

A agricultura permitiu a fixação populacional em torno de determinadas áreas, visto que a ideia de apropriação da terra, cerne do conceito inicial de propriedade, é a célula matter da formação da urbe. A ligação entre a agricultura e o surgimento das cidades é intrínseca, de tal forma que as primeiras cidades surgiram exatamente nos locais onde a agricultura já apresentava elevado estágio de desenvolvimento, ou seja, na Ásia.

Num segundo momento, a entrada de novas tecnologias na agricultura permitiu um excedente de produção capaz de levar o homem rural a buscar novas atividades. O surgimento de novas tecnologias é o próximo passo para o surgimento das cidades, pois quando o homem começa a dominar um elenco de técnicas menos rudimentares que lhe permitem atrair algum excedente agrícola, é um segundo impulso para o surgimento das cidades, visto que ele pode agora dedicar-se a outra função que não a de plantar.

Há certa dificuldade em se formar um conceito de cidade, e esta dificuldade se dá porque diversos são os parâmetros e olhares lançados para elas. Questiona-se se as cidades seriam as ruas e prédios que as formam, ou as pessoas que as habitam.

Para Lefebvre (200 I), o essencial para o entendimento do "fenômeno urbano" é a leitura da cidade a partir de sua centralidade. Nesta, toda a diversidade de coisas, objetos, pessoas, mercadorias, formas, imagens, símbolos etc. se produz e se encontra, causando o típico espetáculo do urbano. Por isso, pode-se, por ela, evidenciar a função (política e administrativa, comercial, produtiva e/ou de serviços), a estrutura (morfológica e sociológica) e a forma (disposição espacial), urbanas.

As relações humanas foram as estruturas que propiciaram a formação das cidades, mas a determinação do que é e como deve ser a cidade emerge na civilização contemporânea. $\bigcirc$ crescimento urbano é justificado principalmente pela migração rural-urbana (SPOSITO, 2005 apud BAZOLLI, 2007).

Mas pode-se considerar o processo de industrialização como o grande 


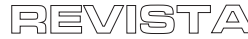

responsável pela explosão da urbanização nos países desenvolvidos e em escala mundial, o qual também foi o responsável pela grande maioria de problemas urbanísticos atuais.

O crescimento das cidades e a importância que estas passaram a ter na vida das sociedades praticamente se consolidaram com o estabelecimento da indústria como atividade essencialmente urbana, pois permitiu não apenas um profundo êxodo rural, mas também as cidades começaram a ser palco de todas as atividades humanas: habitação, lazer, segurança, trabalho e outros.

Nessa vertente, Jacobi (2002, p. 386) traz que a reflexão em torno das práticas sociais num contexto urbano marcado pela degradação permanente do meio ambiente construído e do seu ecossistema maior não pode prescindir nem da análise dos determinantes do processo nem dos atores envolvidos e das formas de organização social que potencializam novos desdobramentos.

Com a consolidação dessas novas atividades urbanas, a cidade ganhou força, sendo que, atualmente em grande parte dos países desenvolvidos e em desenvolvimento, a maioria da população é urbana, ou seja, vive em cidades.

Pode-se afirmar que o conceito contemporâneo de cidade pode ser definido como o espaço físico capaz de proporcionar aos seus habitantes, moradia, trabalho, recreação e circulação humana. Embora a lógica do capitalismo permeie diversas relações, a cidade, além de suas relações econômicas, é preponderantemente humana. Nela vivem pessoas que interagem entre si e buscam satisfazer suas necessidades diárias. Não basta pensar que a cidade é o local da concentração dos meios de produção e de pessoas ligadas à divisão técnica e social do trabalho, envolvidas no processo produtivo. A cidade não abriga apenas "máquinas" e "operários". A urbe é o palco de realização dos direitos do cidadão.

A Constituição Federal, de 1988, abordou o tema do ordenamento das cidades brasileiras, com a inclusão do capítulo de política urbana nos artigos I 82 e 183. Destes artigos depreendem-se instrumentos hábeis a efetivar o direito à cidade, quais sejam: o plano-diretor, parcelamento ou edificação compulsórios; imposto sobre a propriedade predial e urbana progressivo no tempo; desapropriação e usucapião especial.

O Estatuto das Cidades (Lei $n^{\circ}$ 10.257, de 200I) regulamentou a estruturação da política urbana e estabeleceu normas que regulam o uso da propriedade para garantir o bem-estar dos habitantes.

Sendo necessário para obtenção de êxito na continuidade da cidade, imperioso se faz o ato de planejar, que, para Mukai (2004, p.3 I), vem a ser um método da aplicação, contínuo e permanente, destinado a resolver 
racionalmente os problemas que afetam a sociedade situada em determinado espaço, em determinada época, por meio de uma previsão ordenada de antecipar suas ulteriores consequências.

Com o emergir da discussão no cenário político e social, a cidade deve ser um local sustentável, a partir da premissa que seja esse espaço um meio pelo qual a população e os empresários se empenham na melhoraria do ambiente natural, construído e cultural, em âmbito local e regional, objetivando o desenvolvimento sustentável global.

\section{CIDADE SUSTENTÁVEL}

Como fora abordado em linhas iniciais, a cidade possui uma característica peculiar que atrai a atenção da maioria da população mundial: ela é o centro de convergência de interesses e contatos, como também facilitadora de adaptação ao meio, considerando-se a oferta de possibilidades de moradia, alimentação e trabalho. Ela é, ao mesmo tempo, palco e espectadora das relações humanas. Estas, em ambiente favorável para desenvolvimento, apoderam-se, com propriedade, de todas as vantagens ofertadas pela urbe.

Com o passar dos tempos, fica claro que as cidades estão à procura de melhor interação com o meio em que se encontram. Não basta estabelecerem-se em determinado local com ânimo definitivo. Necessita-se de que tal conexão com o meio ambiente seja sustentável.

A História demonstra que a cidade, desde seu surgimento, pode ser considerada como ponto de intersecção entre homem e meio ambiente. Contudo, frise-se que este ambiente "facilitador" para o ser humano promoveu (e ainda promove) degradações significativas, não somente para com o espaço onde se encontra inserido, mas também para com todos os que nele habitam. Importante salientar que tais danos ocasionados não são de iniciativa da cidade "estrutura", mas da cidade "seres humanos". Estes sim são os responsáveis pelos desequilíbrios ambientais por meio de suas ações.

A partir do momento em que o homem passou a analisar sua interação com o meio ambiente não mais apenas sob os prismas patrimonial e comercial, uma luz, mesmo que tênue, começou a flamejar. Tem-se a década de 1970 como marco histórico da preocupação do homem para com o meio ambiente, mais especificamente o ano de 1972, em que dezenas - para não dizer centenas - de atores internacionais reuniram-se para avaliar violações a direitos ambientais, com o intuito de verificar a necessidade e possibilidade de 


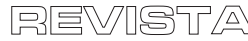

ESMAT SUYENE MONTEIRO DA ROCHA / GUSTAVO PASCHOAL T. DE CASTRO OLIVEIRA

preservação não somente à presente, mas também às futuras gerações.' Verifica-se que a preocupação não é momentânea, pois se estende às gerações futuras. Comprova-se, então, que o senso de responsabilidade pelo que se faz encontra-se vinculado não somente ao tempo presente, mas também para com o que há por vir. Inúmeras tratativas internacionais só passaram a ser realidade depois da Declaração de Estocolmo sobre o Meio Ambiente Humano. Parece, a princípio, que tal situação esteja vinculada somente ao meio ambiente natural. Todavia, não o é. Considerando-se a visão antropocêntrica reflexiva adotada pelo homem, a preocupação ambiental encontra-se também inserida no meio ambiente urbano.

Hans Jonas busca, em sua obra intitulada "O princípio responsabilidade", analisar o referido princípio inserido no contexto atual (e futuro) da ética de uma civilização que avança a passos largos em relação ao desenvolvimento tecnológico. ${ }^{2}$ Não há que se dizer de uma ética para o momento, mas uma ética responsável por uma série de desdobramentos que podem, ou não, ocorrer, levando-se em consideração a exteriorização de pensamentos pela conduta humana. Diz que "Nosso imperativo se estende em direção a um previsível futuro concreto, que constitui a dimensão inacabada de nossa responsabilidade" (p. 49, 2006). Essa situação encontra-se diretamente vinculada à ação humana em relação ao meio ambiente. No que tange ao presente estudo, procura-se vincular o senso de responsabilidade de ações e condutas humanas para com os possíveis caminhos a serem trilhados, buscando a proteção dos presentes e futuros citadinos.

Confirma-se, portanto, que o homem é o responsável pela orientação dos trilhos a serem percorridos pelas cidades. Para êxito em sua missão, deve a sociedade urbana preocupar-se não somente com questões sociais, mas também com as econômicas. Elas devem estar imbricadas por um terceiro eixo: o meio ambiente, mais especificamente, o respeito para com questões ambientais.

Tratado de suma importância é a Declaração do Rio de Janeiro sobre Meio Ambiente e Desenvolvimento que, em seu Princípio 01, estatui: "os seres

'A Declaração de Estocolmo sobre o Ambiente Humano trata do princípio da equidade intergeracional, tanto em seu preâmbulo (itens 6 e 7) quanto nos princípios I e 2 .

${ }^{2}$ Há uma reflexão sobre a ética tradicional, pautada no estudo de consequências próximas ao agir humano. Posteriormente, o autor busca abordar a importância dos reflexos de tais atitudes que perduram no tempo. 
humanos estão no centro das preocupações com o desenvolvimento sustentável. Têm direito a uma vida saudável e produtiva, em harmonia com a natureza". A Conferência das Nações Unidas sobre Meio Ambiente e Desenvolvimento, ocorrida em 1992 na Cidade do Rio de Janeiro, buscou dar seguimento às diretrizes lançadas em 1972 na capital sueca. Frise-se que tal encontro global, bem como os tratados derivados da referida reunião constituem um marco histórico no que tange ao desenvolvimento e aprimoramento dos tratados, fonte maior de Direito Internacional, pois mais uma vez sujeitos e demais atores internacionais encontraram-se reunidos para balizar ações antrópicas, e buscar prever (im)possibilidades ambientais.

A sustentabilidade, tanto em ambiente natural como no artificial, busca equalizar três elementos: social, econômico e ambiental. Não se trata de uma tarefa fácil, pois interesses econômicos - via de regra - conseguem atrair interesses particulares que se sobressaem aos difusos. A construção de um Shopping Center, por exemplo, traz consigo a promessa de um desenvolvimento econômico local, garantindo à cidade maior retorno financeiro, não somente em relação ao fluxo de pessoas que buscarão aproveitar de forma direta de um novo ponto de referência em comércio, mas também na arrecadação de tributos, bem como investidores e especulação imobiliária, gerando, assim, novas possibilidades econômicas para o município. Some-se a este exemplo o interesse de construção do referido centro de compras próximo a uma área de proteção ambiental que contém um córrego já fragilizado pela ação humana. $\bigcirc$ que pode ocorrer, infelizmente, é não se respeitar a questão da sustentabilidade devido às violações de interesse social e ambiental, em relação ao respeito ao meio ambiente sadio, em detrimento de vantagens financeiras. A própria Constituição da República Federativa do Brasil, em seu artigo I 70, estabelece como princípio da ordem econômica e financeira a proteção ao meio ambiente, ou seja, questões de desenvolvimento econômico somente poderão ocorrer caso se respeite o ambiente em que a sociedade encontra-se inserida.

Entenda-se que $\mathrm{o}$ homem possui conexões vitais com 0 meio ambiente, mesmo que não saiba ou ainda não tenha percebido. Trata-se de um relacionamento que traz à tona questões vinculadas ao que se compreende por Direito Natural, ou seja, a necessidade de respeito a um conjunto de direitos considerados como o alicerce para que outros possam subsistir. $\mathrm{O}$ cuidado e respeito para com o meio ambiente é condição sine qua non para dar lugar à prática de demais direitos. Sem uma sólida fundação, toda a edificação tende a ruir. Constata-se da fragilidade humana para com o meio, pois não respeitá-lo 


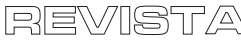

ESMAT

pode gerar consequências desastrosas. Há quem defenda que uma relação equânime entre interesses ambientais, sociais e econômicos faz gerar o que se entende por sustentabilidade fraca, fundamentada no item 05 da Declaração de Johanesburgo sobre Desenvolvimento Sustentável: "por conseguinte, assumimos a responsabilidade coletiva de fazer avançar e fortalecer os pilares interdependentes e que se sustentam mutuamente do desenvolvimento sustentável - desenvolvimento econômico, desenvolvimento social e proteção ambiental - nos âmbitos local, nacional, regional e global".

A princípio pode soar estranho conferir o adjetivo "fraco" a algo que se mostra de uma importância tamanha. Todavia, há de se dizer que o não cumprimento de diretrizes, lançadas desde a década de 1970, fez enfraquecer tal conceituação de sustentabilidade. Soma-se a tal constatação a prática de atitudes antiéticas não pautadas no princípio da responsabilidade, bem como a obstinação de interesses que visam ao lucro a qualquer custo, tanto por particulares quanto por seus representantes.

E na busca por uma correta interação do homem e seus interesses para com o meio ambiente, surge a expressão sustentabilidade forte. Diz Morato que a sustentabilidade forte "é aquela constituída por um fundamento (recursos naturais) e dois pilares (economia e sociedade). Nela, a valoração diferenciada do meio ambiente natural - a biosfera -, em relação à economia e à sociedade, permite uma real proteção do meio ambiente (...)" (2012, pp. 163-164). Busca-se, portanto, com a sustentabilidade forte, erguer a condição ambiental a um patamar diferenciado, não apenas como elemento integrante de uma relação, mas como real estrutura. Verifica-se a necessidade de uma readaptação na visão de sustentabilidade. Tal constatação - mais uma vez, diga-se de passagem - não se encontra vinculada somente ao meio ambiente natural. $\bigcirc$ meio ambiente artificial tem muito a ganhar com tal concepção.

O meio ambiente urbano degrada e fragiliza toda a região de meio ambiente natural onde se encontra inserido. Há de se dizer que o ser humano também é destinatário final de consequências de ações nem um pouco sustentáveis. Infraestruturas, transportes e mobilidade (direito de ir e vir), habitação, energia, abastecimento de água, saneamento básico, saúde e educação são, dentre outros, indicadores de como se encontra a interação entre os elementos componentes do princípio da sustentabilidade em ambiente urbano, seja em sua modalidade forte ou fraca.

Os direitos acima elencados encontram previsão legal não somente na Magna Carta (mais especificamente em diretrizes contidas nos artigos 182 e 183, como fora tratado no início do presente estudo), mas também em normas 
infraconstitucionais. Cite-se como exemplo a Lei n 10.257, de 200 I, também conhecida como Estatuto da Cidade, que tem por finalidade, afora regulamentar os artigos 182 e 183 da Constituição Federal, estabelecer diretrizes gerais de política urbana. Complementando, frise-se da importância da Lei n 12.305, de 20 I0, que instituiu a política nacional de resíduos sólidos que, mesmo de âmbito federal, necessita de trabalhos em esforços municipais, na busca de um meio ambiente equilibrado.

\section{PALMAS: A CIDADE EM SUSTENTAÇÃO OU SUSTENTÁVEL?}

\section{I Palmas: características de um novo ambiente no cerrado}

Dada a riqueza do tema, que abarca uma compreensão histórica de toda a formação, criação e desenvolvimento da cidade, seja ela planejada ou não, serão utilizados vários outros autores no desenvolvimento da pesquisa (assim como fontes documentais e bibliográficas que complementam as temáticas abordadas no projeto).

Historicamente, pode-se pontuar a ocupação do cerrado a partir da colonização goiana, cuja data de início, segundo historiadores, foi em 1592. Entretanto, o processo se deu a partir de expedições lideradas por jesuítas que buscavam índios para catequização ou escravidão, isso porque Goiás era um território indígena. (MORAES, 2006)

Duarte (2006, p. 102), ao analisar a formação e estruturação da cidade e sua imagem, estabelece que a ocupação do lugar tenha como condicionantes os elementos geográficos, climáticos, circunstâncias ecossistêmicas de manutenção da vida. A primeira grande expansão migratória de Goiás se deu no período da descoberta do ouro, entre 1726 e 1749. Assim, em I94I, a região de Goyazes foi desmembrada pela corte Portuguesa e elevada à categoria de Capitania. Nos idos de 1800, as expedições almejavam de forma direta a obtenção de mão de obra para os barcos e trabalho na pecuária.

Se a ocupação inicial do Centro-Oeste se deu de forma contundente no século XVII, o movimento de expansão do território brasileiro nos novos tempos se caracteriza com a proposta de ocupação do Planalto Central, formando assim novos espaços e cenários políticos, tudo regido sob a Marcha para o Oeste. (MORAES, 2006).

A capital da Capitania de Goyazes foi a cidade de Goiás. Mas, para a ocupação do cerrado, seria necessário trazer um olhar moderno e crescimento para a região Centro-Oeste, e assim, formar um novo modelo de urbanização 


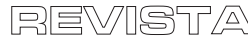

ESMAT SUYENE MONTEIRO DA ROCHA / GUSTAVO PASCHOAL T. DE CASTRO OLIVEIRA

para o Goiás que até então se caracterizava predominantemente rural.

Fazendo uma construção temporal, Santos (2006) estabelece que, na Era Vargas ( 1930- 1945), o poder público passou a promover a produção direta e o financiamento da moradia urbana; já no período do regime militar (I9641985), o planejamento urbano foi elevado à condição de prioridade nas políticas governamentais.

O discurso de modernidade para o Centro-Oeste se torna a tônica e o anseio da transformação do sertão goiano em novo espaço urbano e leva à criação e formação de uma nova capital, Goiânia, cidade projetada e planejada, tendo sido fundada em 24 de outubro de 1933, e absorvido a função de capital do estado de Goiás, em 1937.

Palmas foi criada para ser a capital do estado do Tocantins, o último Estado criado com o advento da Constituição Federal, de 1988, como se observa no art. 13 dos Atos e Disposições Constitucionais Transitórias (ADCT). ${ }^{3}$ A cidade foi a última capital planejada do século $X X$, no Brasil, tendo sido sua implementação determinada pela Lei Estadual $n^{\circ} 70$, de 1989, Lei esta revogada pela Lei n ${ }^{\circ}$ 106, de 19/12/1989.

Fatores geográfico-econômicos e políticos motivaram a escolha do lugar a ser criada a cidade de Palmas, à margem direita do rio Tocantins, considerandose o sentido Sul-Norte, localizada no centro geográfico do Estado. Como medida administrativa, na ocasião, foi desmembrada do Município de Porto Nacional a área de 1.024 quilômetros quadrados, englobando a localidade de Taquaralto e de Taquarussu do Porto (BAZOLLI, 2007, p. 82). Todavia, a primeira capital do novo Estado Brasileiro foi a cidade de Miracema do Tocantins, sendo Palmas fundada no dia 20 de maio de 1989, vindo a se tornar a capital do Estado somente em $1^{\circ}$ de janeiro de 1990. A partir desse momento, o município de Taquarussu do Porto passa a ser considerado distrito da nova capital, e a ser englobado em sua área de influência.

O nome da capital foi em homenagem à Comarca de São João da Palma, hoje a atual cidade de Paranã. O planejamento da cidade se iniciou antes mesmo de sua instalação, o traçado das avenidas e a modelação das quadras foram elaborados por um grupo de arquitetos e engenheiros, no intuito de tornarem a cidade um modelo de desenvolvimento e sustentabilidade ambiental.

\footnotetext{
${ }^{3}$ Diz o caput: "É criado o Estado do Tocantins, pelo desmembramento da área descrita neste artigo, dando-se sua instalação no quadragésimo sexto dia após a eleição prevista no § $3^{\circ}$, mas não antes de I ' de janeiro de 1989".
} 
O plano urbanístico de Palmas, descrito na Lei $n^{\circ} 468$, de 1994 , compreendia como a área urbana da cidade as áreas determinadas no plano urbanístico, além das áreas ocupadas nos distritos de Taquaruçu (à época, escrito Taquarussú), Taquaralto, Canela e o povoado de Buritirana (artigo $3^{\circ}$ ).

A região de Taquaralto é hoje considerada como uma extensão da sede do município, não sendo mais considerado distrito, como o era de acordo com a Lei n ${ }^{\circ} 468$, de 1994. Tal fato foi benéfico à região, pois ao ser englobado como sede do município propiciou melhoria na infraestrutura e desenvolvimento local, apesar de possuir características físicas e populacionais diferenciadas da capital.

Com o rápido crescimento da capital, sua área de abrangência se tornou muito mais evidente. A população crescia cada vez mais, e isso estendia a área urbana da cidade para locais não planejados, o que resultou numa dispersão física da cidade. Desse modo, foi elaborado um plano estratégico de desenvolvimento metropolitano de Palmas, Lei no 829, de 1999, cuja finalidade era a de "definir políticas e implementar ações, no sentido de dotar, mediante a mobilização de todos os segmentos da sociedade, de um desenvolvimento planejado que possa integrar a sua função de Capital do Estado, num contexto Metropolitano, com um crescimento intencional, que concilie desenvolvimento econômico com a melhoria da qualidade de seus habitantes".

A História de Palmas se entrelaça com os ideais de desenvolvimento sustentável e meio ambiente sadio, justamente o proposto pela Constituição de 1988. Assim, debruçar o olhar sobre o planejamento de uma cidade perpassa, obrigatoriamente, por um plano político. Pode-se afirmar que Goiânia foi fruto de Pedro Ludovico; Brasília, de Juscelino Kubitschek; e Palmas, de Siqueira Campos. (MORAES, 2006, p. I I6).

A dinâmica espacial que origina as cidades está representada pelo processo contínuo de alocação de formas construídas, espaços adaptados e atividades sociais sobre determinado locus. O ajuste espacial é decorrente das forças, dos contrastes e dos privilégios, determinantes na diferenciação da maneira de ocupação, coordenadas pelos atores sociais que agem sobre os elementos urbanos, ora provocando aglomeração de pessoas e concentração de atividades, ora dispersando as pessoas e descentralizando as atividades, estabelecendo, assim, a cada ação de transformaçãa, um novo mapa de acessibilidade com seu quadro de beneficiários (BAZOLLI, 2007, p 34).

Importante ressaltar que projeto político deve responder às demandas e interesses da população. Para tal obtenção, deverão estar disponíveis: recursos técnicos, materiais, econômicos e humanos. Essa racionalidade implica analisar 


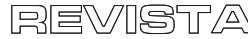

ESMAT SUYENE MONTEIRO DA ROCHA / GUSTAVO PASCHOAL T. DE CASTRO OLIVEIRA

gastos, custos e benefícios, articulando-se com grupos não hegemônicos e buscando, pelo menos, o desenvolvimento institucional da sociedade. Junto a essa racionalidade política, o contexto internacional acaba tendo peso forte, pois pactos e alianças acabam sendo realizados.

\subsection{Palmas hoje - gestão de cidades: instrumentos da política urbana}

Após pesquisas em documentação obtida por meio de leituras de doutrina e legislação (nacional, estadual e local), buscou-se tratar sobre a questão da sistematização de normas e preocupação de sujeitos envolvidos com o município de Palmas-TO.

Trata o Plano-Diretor de peça fundamental para com assuntos vinculados à gestão das cidades. Tal assunto é tratado pelo artigo $182 \mathrm{da}$ Constituição da República Federativa do Brasil, de 1988, ao discorrer sobre política urbana (Capítulo II, Titulo VII "Da ordem econômica e financeira"). Para se colocar em prática o "pleno desenvolvimento das funções sociais da cidade e garantir o bem-estar de seus habitantes" (caput art. 1 82) é de suma importância tanto a elaboração do Plano-Diretor (pelo Poder Legislativo Municipal) como a instauração de políticas públicas correlacionadas (pelo Poder Executivo Local), para se conseguir cumprir o solicitado pelo Princípio Geral de Direito da função social da propriedade, inclusive.

No que tange à legislação infraconstitucional, verifica-se a importância das disposições normativas contidas na Lei n 10.257, de 200। (Estatuto da Cidade), mais especificamente no tocante ao conteúdo dos artigos 39 ao 42-B (Capítulo III "Do Plano-Diretor"). Tais artigos possuem valiosas informações para com a (não) constatação/implantação/acompanhamento da sustentabilidade nos municípios, como: função social da propriedade; instituição e revisão do plano-diretor; audiências públicas e publicidade; ampliação do

\footnotetext{
${ }^{4}$ Evidencia-se essa regulação por meio da lógica do razoável, que, nos dizeres de Lafer, “(...) é razoável, no clima espiritual da modernidade, preocupar-se com o alcance e os limites epistemológicos dos procedimentos intelectuais que caracterizam a prática do Direito. É igualmente razoável procurar definir o Direito pela sua forma quando o processo de contínua mudança do Direito Positivo, por obra das necessidades de gestão da sociedade moderna, tomou impraticável definir o jurídico pelo seu conteúdo. É também razoável lidar com o descompasso entre a norma formal e a realidade social quando este descompasso se generaliza. Finalmente, é razoável discutir criticamente os valores de Justiça contidos no Direito Positivo diante da crise generalizada de legitimidade do poder que positiva a legalidade". (| 988, p. | 8).
} 
perímetro urbano.

Importante salientar a necessidade da aplicação de técnica de interpretação lógica, tanto nas modalidades interna, externa e do razoável, para com a Lei em questão. Internamente, há de se dizer da constatação de coerência de todos os assuntos abordados nos Capítulos I (Diretrizes Gerais), II (Dos Instrumentos da Política Urbana), III (Do Plano-Diretor), IV (Da Gestão Democrática da Cidade), V (Disposições Gerais); externa, em relação à resposta positiva do conteúdo da lei para com o que é almejado por toda a sociedade (e, neste caso, vê-se cumprir o que se encontra estabelecido no caput do art. 225 da CF, de 1988); e, por fim, da lógica do razoável, ou seja, do bom senso da aplicação dos dispositivos legais, levando-se em consideração necessidades correlacionadas às demandas locais/temporais). ${ }^{4}$

Constata-se aplicação da técnica sistemática, devido à conexão com questões tratadas pela própria CF, de 1988, bem como com a possibilidade de conexão com outras leis infraconstitucionais que sejam necessárias para a implantação de políticas públicas em relação às necessidades locais (municipais).

Como dito anteriormente, tem-se como um dos princípios da Ordem Econômica e Financeira da República Federativa do Brasil a "defesa do meio ambiente, mediante tratamento diferenciado, conforme o impacto ambiental dos produtos e serviços e de seus processos de elaboração e prestação" (inciso VI, art. 170, que versa sobre os princípios da Ordem Econômica e Financeira), ou seja, trata-se de dispositivo que tem por finalidade assegurar saudável interação de questões sociais, ambientais e econômicas. $\bigcirc$ estudo sobre o Estatuto da Cidade vem para somar, demonstrando que, para a correta evolução da cidade de Palmas, mister se faz a integração de tais elementos. Diz Granziera que

(...) a sustentabilidade urbana não diz respeito apenas ao meio ambiente. Quando o Estatuto da Cidade define o direito às cidades sustentáveis, como sendo o direito à terra urbana, à moradia, ao saneamento ambiental, à infraestrutura urbana, ao transporte e aos serviços públicos, ao trabalho e ao lazer, para as presentes e futuras gerações, evidencia-se a complexidade que envolve a expressão, abrangendo fatores econômicos, sociais, culturais e políticos (201 I, p. I.245).

Evidencia-se, portanto, a necessidade de se estabelecer um fio condutor, começando pela questão da sustentabilidade, perpassando por questões doutrinárias e legais sobre Estatuto da Cidade e Plano-Diretor para, posteriormente, tratar sobre questões de sustentabilidade local (a visão e construção do conceito no município de Palmas). 


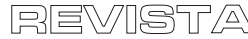

No que tange à Lei Orgânica do Município de Palmas-TO, constatam-se dispositivos que se encontram conectados com a questão da sustentabilidade do município ora analisado, qual seja, a questão da (não) percepção de sustentabilidade no município de Palmas, capital do estado do Tocantins. A Lei Orgânica do Município traz preciosas informações em seu artigo $5^{\circ}$, a saber:

Art. $5^{\circ}$ - Ao Município de Palmas compete prover tudo quanto respeite ao interesse local e ao bem-estar de sua população, cabendo-lhe, entre outras, as seguintes atribuições:

$[\ldots]$

VII - elaborar o seu Plano Diretor;

VIII - promover o adequado ordenamento territorial, mediante planejamento e controle do uso, do parcelamento e da ocupação do solo urbano;

$[\ldots]$

XXII - promover a proteção do patrimônio histórico e cultural local, observada a legislação e ação fiscalizadora federal e estadual;

XXIII - promover a preservação da flora e da fauna de seu território, combatendo qualquer forma de poluição;

XXIV - promover e incentivar o turismo local, como fator de desenvolvimento econômico e social, inclusive contribuindo com a União e o Estado no combate à caça e à pesca predatórias;

$X X V$ - quanto aos estabelecimentos industriais, comerciais e similares:

a) conceder ou renovar licença para instalação, localização e funcionamento;

b) revogar as licenças daqueles cujas atividades se tornarem prejudiciais à saúde, à higiene, ao bem-estar, à recreação, ao sossego público e aos bons costumes;

c) promover o fechamento daqueles que funcionarem sem licença ou em desacordo com a lei;

d) dispor sobre plantões comerciais e de serviços no interesse da coletividade;

e) assegurar sem o estabelecimento de limite de som amplificado ou não o livre exercício dos cultos religiosos e suas liturgias, nos templos e /ou espaços públicos, conforme o disposto na Constituição Federal, artigos. 5, VI; I9, I, II; 30,1 , II.

De acordo com o que fora mencionado, percebe-se que a presente legislação preocupou-se, em seu artigo quinto, de tratar sobre os tipos de meio ambiente, quais sejam, natural, artificial, cultural e, de certa forma, do trabalho. Encontra-se um encadeamento de ideias com o artigo seguinte, artigo sexto, ao dispor sobre a preocupação com a proteção ao meio ambiente natural e meio ambiente urbano, considerando-se o que se entende por sustentabilidade forte efraca.

Como já sustentado anteriormente, a sustentabilidade fraca busca reunir como fundamentos meio ambiente, sociedade e economia, conferindo a estes três elementos o mesmo patamar, em igual importância. Já a sustentabilidade 
forte confere ao meio ambiente o status de fundamento, cabendo aos outros dois elementos (sociedade e economia) figurarem em um grau inferior. Tal definição tem por objetivo assegurar que todos possam ter acesso ao meio ambiente equilibrado. Este, por sua vez, é a somatória entre meio ambiente sadio e saúde humana. Percebe-se, portanto, a necessidade de se promover, por meio de políticas públicas, correlação entre esses elementos, buscando a sustentabilidade no município.

Oartigo 10, no tocante à competência legislativa do município, também aborda assuntos ligados ao tema. Diz, em seus incisos I e X, que compete à Câmara legislar sobre:

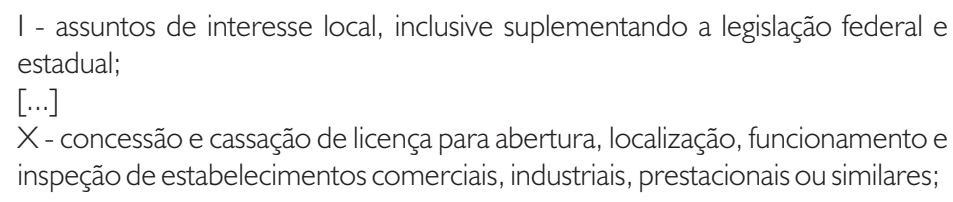

I - assuntos de interesse local, inclusive suplementando a legislação federal e estadual;

$[\ldots]$

X-concessão e cassação de licença para abertura, localização, funcionamento e inspeção de estabelecimentos comerciais, industriais, prestacionais ou similares;

Informações importantíssimas sob dois aspectos vêm à tona: possibilidade de legislação municipal no que tange a assuntos ambientais (inciso I, diga-se de passagem, com o devido amparo constitucional), bem como a necessidade de a Administração Pública intervir em empreendimentos, privados ou públicos, no tocante ao licenciamento ambiental, cumprindo as devidas etapas, quais sejam, prévia, instalação e operação, considerando-se o disposto na Resolução n 237 , de 1997, do Conselho Nacional do Meio Ambiente (CONAMA), Anexo I (empreendimentos que, obrigatoriamente, deverão se submeter ao procedimento de licenciamento ambiental).

O artigo 38 traz informações sobre Leis Complementares. No estudo em questão, interessa o que se encontra disposto em seu inciso IV: o Plano-Diretor do Município dá-se por Lei Complementar. O Plano-Diretor do Município de Palmas possui redação em Lei Complementar n I 55, de 2007. Tal assunto será abordado com mais detalhes após a apresentação de dispositivos da Lei Orgânica do Município de Palmas, considerados como de grande importância para a pesquisa em questão.

Em relação à Lei Orgânica, encontram-se, em seu Título III (Organização Municipal), no Capítulo I (Do Planejamento Municipal), os artigos 88 e 89, com a seguinte redação:

Art. 88 - O Município deverá organizar a sua administração, exercer suas atividades e promover sua política de desenvolvimento urbano dentro de um 
planejamento permanente, atendendo os objetivos e diretrizes estabelecidas no Plano Diretor e mediante adequado Sistema de Planejamento.

$\S 1^{\circ}$ - O Plano Diretor é o instrumento orientador e básico dos processos de transformação do espaço urbano e de sua estrutura territorial, servindo de referência para todos os agentes públicos e privados que atuam na cidade.

$\S 2^{\circ}$ - Sistema de Planejamento é o conjunto de órgãos, normas, recursos humanos e técnicos voltados à coordenação da ação planejada da Administração Municipal.

$\S 3^{\circ}$ - Será assegurada pela participação em órgão componente do Sistema de Planejamento, a cooperação de associações representativas, legalmente organizadas, com o planejamento municipal.

Art. 89 - A delimitação da zona urbana será definida por lei, observado o estabelecimento no Plano Diretor.

$\bigcirc \S 1^{\circ}$, de acordo com o disposto na Carta Magna, dita sobre a essência do Plano-Diretor, enquanto que o $\S 3^{\circ}$ garante a participação efetiva de todos os interessados no planejamento do município, cumprindo, assim, o que dispõe o caput do artigo 225 da Constituição Federal ("Todos têm direito ao meio ambiente ecologicamente equilibrado, bem de uso comum do povo e essencial à sadia qualidade de vida, impondo-se ao Poder Público e à coletividade o dever de defendê-lo e preservá-lo para as presentes e futuras gerações" grifo nosso). No capítulo IV do presente título, encontram-se no artigo 95 informações sobre obras e serviços municipais, ao estatuir que "a realização de obras públicas municipais deverá estar adequada às diretrizes do Plano Diretor". Para tanto, mister se faz a análise minuciosa de tal Lei Complementar (I 55, de 2007), para devida interpretação sistematizada.

Por fim, no que toca à Lei Orgânica do Município, há de se dizer do conjunto de artigos encontrados entre o 160 e 184, que tratam sobre questões concernentes à Ordem Econômica e Social (Título V, Capítulo III "Da Saúde" I 60 a I 62 -; Capítulo VI "Da Política Urbana" - I78 a I8I -; Capítulo VII "Do Meio Ambiente" - 182 e seguintes).

\section{CONSIDERAÇÕES FINAIS}

Subentende-se, pelo surgimento das cidades, a necessidade humana de contato, reafirmando sua vocação para a vida em sociedade. $\bigcirc$ meio ambiente artificial propicia convergência entre interesses no que tange à efetivação de direitos tidos como fundamentais, especialmente os sociais.

De acordo com o que se encontra posto pela doutrina, legislação e jurisprudência, o direito à cidade é considerado como condição sine qua non para a concretização dos demais direitos advindos do compartilhamento de 
espaço. Por mais que as evidências apontem para convergências, há de se falar também sobre divergências. Essa preocupação se encontra inserida não somente em documentos legais locais, mas também nos de âmbito internacional, como, por exemplo, a Declaração de Estocolmo sobre o Ambiente Urbano, Declaração do Rio de Janeiro sobre Meio Ambiente e Desenvolvimento, e a Declaração de Johanesburgo sobre Desenvolvimento Sustentável.

Em relação à sustentabilidade, evidenciou-se pelos estudos realizados a diferenciação doutrinária entre sustentabilidade fraca e forte. A sustentabilidade fraca se encontra contida em tratativas internacionais, inclusive, - como o disposto na Declaração de Johanesburgo - fazendo com que os elementos sociais, econômicos e ambientais figurem num mesmo patamar. Já a sustentabilidade forte elege o meio ambiente como pilar de sustentação, fazendo com que os demais (social e econômico) gravitem em torno desta, na busca da devida aplicação do princípio da responsabilidade ética para com o próximo e para com o futuro comum, com vistas à devida equidade intergeracional.

Verificou-se, com a realização da pesquisa, que tais preocupações não são privilégios/preocupações concernentes somente ao meio ambiente natural. O meio ambiente urbano necessita dos devidos cuidados para com a aplicação do que se entenda por sustentabilidade, seja ela na modalidade fraca ou forte. O que definirá a variante é a percepção humana para com o devido cuidado do espaço no qual se encontra inserida.

Para melhor delimitação do tema, buscou-se analisar dispositivos legais que vêm ao encontro da proteção e regulamentação de direitos à cidade no município de Palmas-TO.

Após pesquisas em documentação obtida por meio de leituras de doutrina e legislação (nacional, estadual e local), buscou-se tratar sobre a questão da sistematização de normas e preocupação de sujeitos envolvidos com o município de Palmas-TO. Constataram-se em seu Plano-Diretor importantíssimas diretrizes para a gestão de questões referentes ao Direito Urbanístico local, com a devida observação de dispositivos constitucionais.

Importante salientar a devida sistematização com a legislação infraconstitucional, como, por exemplo, as devidas conexões com o preconizado pela Lei n ${ }^{\circ}$ 0.257, de 200 I, e com a Lei Orgânica do Município, que buscam disciplinar, dentre outros pontos, sobre a política de desenvolvimento urbano local, de acordo com os direcionamentos encontrados no Plano-Diretor. 


\section{REVIESA}

ESMAT SUYENE MONTEIRO DA ROCHA / GUSTAVO PASCHOAL T. DE CASTRO OLIVEIRA

Trouxe à baila informações sobre duas outras cidades planejadas do cerrado: Goiânia e Brasília. Palmas, a mais nova entre as três, possui a vantagem de analisar aspectos positivos e negativos das demais, buscando absorver as lições, transformando-as em benefícios para os que nela habitam. Por mais que tenha sido planejada em todos os aspectos que se podia imaginar, mas o passar dos tempos mostra a esta jovem capital situações e problemas dantes não imaginados, seja pelo avanço técnico-industrial, seja pela natural consequência de ações humanas nos diferentes níveis que compõem a sustentabilidade. É de suma importância o engajamento político e social, para que se consiga permanecer nos trilhos traçados pelo desenvolvimento sustentável. $\bigcirc$ agir local trará benefícios a todos, seja em tempo presente, seja em tempo futuro, tanto para habitantes quanto para a estrutura artificial criada, dentro de uma perspectiva antropocêntrica reflexiva.

\section{REFERÊNCIAS}

BRASIL. Constituição da República Federativa do Brasil de 1988. Disponível em:

<http://www.planalto.gov.br/ccivil_03/constituicao/constituicao.htm>. Acesso em I 2 abr. 2014.

.Política Nacional de Desenvolvimento Urbano. Disponível em:< http://www.unc.br/mestrado/mestrado_materiais/I PoliticaNacionalDesenvol vimentoUrbano.pdf > . Acesso em I 0 fev. 2014.

.Governo Federal. Lei 10.257 de 10 de Julho de 2001 . Disponível em:< http://www.planalto.gov.br/ccivil_03/leis/leis_200 I/l 0257.htm>. Acesso 5 mar. 2014.

.Lei II.124 de 16 de junho de 2005. Disponível em:< http://www.planalto.gov.br/ccivil_03/_ato2004-2006/2005/lei// I I 24.htm>. Acesso em 6 mar. 2014.

.Lei II.445 de 5 de janeiro de 2007. Acesso em:< http://www.planalto.gov.br/ccivil_03/_ato2007-20 I 0/2007/lei/l I I 445.htm >. Acesso em 6 mar. 2014. 
.Lei 12.305 de 02 de agosto de 2010. Disponível em:< http://www.planalto.gov.br/ccivil_03/_ato2007-20 I 0/20 I 0/lei/l I 2305.htm $>$. Acesso em $1^{\circ}$ abr. 2014.

.Lei 12.587 de 3 de janeiro de 2012. Disponível em:< http://www.planalto.gov.br/ccivil_03/_ato20 I I-20 I 4/20 I 2/lei/l I2587.htm>. Acesso em I 5 abr. 2014

- Lei 12.608 de 10 de abril de 2012.Disponível em:< http://www.planalto.gov.br/ccivil_03/_Ato20II 2014/20 I2/Lei/LI2608.htm\#art24>. Acesso em 5 maio. 2014.

BAZOLLI, João Aparecido. Os Efeitos dos vazios urbanos no custo de urbanização da Cidade de Palmas - TO. Universidade Federal do Tocantins: 2007. (Dissertação de Mestrado)

DUARTE, Eduardo. Desejo da cidade - múltiplos tempos, das múltiplas cidades, de uma mesma cidade. In: PRYSTHON, Ângela (org.). Imagens da Cidade: espaços urbanos na comunicação e cultura contemporânea. Editora Sulina, 2006.

GRANZIERA, Maria Luiza Machado. Meio ambiente urbano e sustentabilidade. In: MILARÉ, Édis; MACHADO, Paulo Afonso (Org.). Doutrinas essenciais de direito ambiental: meio ambiente urbano. São Paulo: Revista dos Tribunais, 2011.

JACOBI, Pedro, Meio ambiente urbano e sustentabilidade: alguns elementos para a reflexão. In: CAVALCANTI, Clóvis. (org) Meio Ambiente, Desenvolvimento sustentável e políticas públicas. São Paulo: Cortez Editora, Recife: Fundação Joaquim Nabuco, 2002.

LEFEBVRE, Henri. O Direito à cidade. São Paulo: Centauro, 200 I .

MORAES, Lúcia Maria. A segregação planejada: Goiânia, Braślia e Palmas. Goiânia. Editora UCG, 2006.

MUKAl, Toshio. Temas atuais de direito urbanístico e Ambiental. Belo Horizonte. Editora Forum, 2004. 
PALMAS. Lei municipal 829, de 08 de julho de 1999. Institui o plano estratégico de desenvolvimento metropolitano de Palmas e adota outras providências. Disponível em: < http://20 I.90. 134.5 I/portal/noticia/buscalei > Acesso em I6 mar. 2014.

SANTOS, Ângela Moulin S. Penalva. Planejamento urbano: para quê e para quem? In: Revista de Direito da Cidade. Programa de Pós Graduação em Direito. Faculdade de Direito, nº 0 I (maio 2006) Rio de Janeiro, Harbra, 2006, v. I. 